\title{
Relationship Patterns Associated with Dimensions of Vulnerability to Psychopathology
}

\author{
Nicholas B. Allen, ${ }^{1,2}$ Nick Haslam, ${ }^{1}$ and Assaf Semedar ${ }^{1}$
}

Associations between vulnerability to psychopathology and atypical ways of perceiving and conducting relationships were investigated in a study of 350 undergraduates. Self-report measures of traits associated with vulnerability to depression, bipolar disorder and psychosis were used to predict atypical relationships with family members, close friends, student peers, and authority figures. Tendencies to implement four basic relational models in personal relationships of each type were examined. Depressionproneness was associated with tendencies to apprehend family and close friend relationships in unusually close and asymmetrical ways. Vulnerability to bipolar disorder was manifest in relationships with authority figures, which vulnerable individuals conducted in an unusually communal and egalitarian manner. Psychosis-proneness was associated with two distinct patterns. Socially anhedonic individuals were less apt than others to view family and close friend relationships as warm and balanced, and viewed relations with friends in a hierarchical fashion. This perception of asymmetry in friend and also family relationships was also apparent among individuals with more "positive" schizotypal features. Atypical relational patterns appear to be associated with vulnerability for major mental disorders.

KEY WORDS: relational models; social cognition; psychopathology; vulnerability; dysthymia; hypomania; schizotypy; social anhedonia.

\section{RELATIONSHIP PATTERNS ASSOCIATED WITH VULNERABILITY TO PSYCHOPATHOLOGY}

Disturbances in interpersonal functioning are prominent features of most forms of psychopathology. Impaired social cognition may be a critical mediator of these processes, compromising the ability to process interpersonal information (Broks, 1997) and to function adaptively in social contexts (e.g., Blanchard, Mueser, \& Bellack, 1998). For instance, interpersonal processes play an important role in the

\footnotetext{
${ }^{1}$ University of Melbourne, ORYGEN Research Centre.

${ }^{2}$ Correspondence should be directed to Nicholas B. Allen, ORYGEN Research Centre, Department of Psychology, University of Melbourne, Victoria 3010, Australia; e-mail: nba@unimelb.edu.au.
} 
development and maintenance of depression (Segrin \& Abramson, 1994), where it has been shown that depressed people tend to elicit rejection from others (Coyne, 1976). Social cognition is also markedly abnormal in depressed individuals, who endorse beliefs that are likely to result in negative interpretations of interpersonal situations (e.g., "People will think less of me if I make a mistake"; Dohr, Rush, \& Bernstein, 1989; Lewinsohn, Steinmetz, \& Larson, \& Franklin, 1981), and direct their attention towards stimuli indicating "social threat" (Mathews, Ridgeway, \& Williamson, 1996). This hypervigilance towards social threat, which may be adaptive in circumstances of genuine threat to social well-being, may result in markedly maladaptive social behavior when benign social cues are misclassified as threatening (Allen \& Badcock, 2003; Badcock \& Allen, 2003). Interpersonal dependency and excessive reassurance seeking are examples of the sorts of maladaptive social behaviors that might emerge from such a misclassification and are strongly associated with vulnerability to depression (Coyne \& Whiffen, 1995; Joiner \& Schmidt, 1998).

Interpersonal processes have also been recognized as important factors in the development and maintenance of schizophrenia-spectrum disorders (Penn, Corrigan, Bentall, Racenstein, \& Newman, 1997). In addition to deficits in general cognition and interpersonal behavior, the schizophrenias have been found to involve specific abnormalities of social cognition (e.g., Corrigan \& Toomey, 1995; Frith \& Corcoran, 1996; Penn, Spaulding, Reed, \& Sullivan, 1996). A number of such abnormalities have been discussed, including deficits in the perception of emotion in other people (e.g., Edwards, Jackson, \& Pattison, 2002) and more general deficits in being able to infer the mental states of others (i.e., a deficit in "theory of mind"; Frith \& Corcoran, 1996). Bentall (2001) has recently discussed how these biases and deficits in social cognition might combine to produce symptoms of paranoia, and other socially oriented delusions, where the social world is seen as excessively hostile and dangerous.

Interpersonal problems have also been associated with symptoms of bipolar affective disorder, and one of its putative phenotypic precursors, hypomanic personality. These problems have included high expressed emotion in families and low levels of social support more generally (Johnson \& Meyer, 2003; Klein, Lewinsohn, \& Seeley, 1996). Unfortunately relatively little is understood about the social cognitive deficits that might underlie such processes in those suffering from, or at risk of, bipolar disorder, but there are some suggestive recent findings. Neale (1988) has provided a modern interpretation of the classic psychoanalytic concept of manic defense, suggesting that one of the core symptoms of mania, grandiose ideas, is generally precipitated when distressing thoughts or psychosocial stress begin to overwhelm the person. The mood elevation and other manic symptoms then act to keep such distressing thoughts out of consciousness (Neale, 1988). This hypothesis predicts that during mania there is dissociation between the explicit presentation of the self (i.e., as powerful, loved, admired) and the implicit or latent categorization of the self (i.e., as powerless, unlovable). In support of this model Lyon, Bentall and Startup (1999) found that both manic and depressive patient groups attributed more negative than positive events to self, and demonstrated slowed color naming of depression-related words in a Stroop task. However, like the control group, manic 
patients explicitly endorsed more positive words as true of self. Such a dissociation between implicit and explicit self-concepts would likely cause considerable problems in interpersonal relationships, especially hierarchically oriented relationships, where the bipolar person's defensive tendency to see themselves in excessively powerful and attractive terms may prevent them from engaging in adaptively submissive behavior when dealing with superiors.

Despite the dramatic advances that have been made in studying interpersonal and social-cognitive aspects of mental disorders, a number of issues remain to be clarified. First, most investigations of such phenomena have compared a single disorder to a healthy comparison group. Second, in order to clarify which processes are etiologically significant, as opposed to those features that are primarily associated with the acute or residual phases of the disorder, it is important to study phenotypic variations in vulnerability to disorder. This also appears to be a lacuna in the literature. For example, Penn and colleagues (1997) have pointed out there is very little research on social cognition with populations at risk of schizophrenia, and similar assertions can be made regarding affective disorders (Sacco, 1999). Finally, relatively little of the research to date has utilized a comprehensive model of human social cognition, and the social behavior that emerges from it, to organize the examination of disordered social cognition and behavior in psychopathology. Such a model is offered by Fiske's (1992) work on relational models.

Relational models theory (Fiske, 1992) proposes four fundamental cognitiveaffective models in terms of which people interpret, construct, evaluate, and seek social relationships. The Communal Sharing model structures relationships in terms of equivalence and shared identity, in which members of a group or dyad perceive themselves as an undifferentiated unit, and is often exemplified by romantic and family relationships. The Equality Matching model, which often governs relations with friends and colleagues, is based on balanced egalitarian reciprocity, manifested in turn-taking and keeping track of favors and obligations. Authority Ranking represents relationships in asymmetrical and hierarchically ordered terms, based on differences in status, knowledge, or power. Market Pricing, finally, construes relationships in terms of proportionality or equity, using socially meaningful ratios such as rates of return on time, effort or investment, and often but not always involves money.

In theory, the four relational models are universal and discrete, and frequently govern relationships in combination, with research consistently supporting these claims (Fiske, 1993; Haslam, 1994; Haslam \& Fiske, 1999). An extensive empirical literature supports the capacity of the RMs to illuminate an assortment of social-cognitive and interactional phenomena (see Fiske \& Haslam, 1996; Haslam, 2004, for reviews). For example, the models have been shown to organize implicit and explicit classification of personal relationships, to guide judgments of relationship prototypicality, to predict the patterning of social errors and social activity planning, to underpin person memory, and to influence judgments of relational transgressions.

Although relational models theory has garnered extensive support as an account of the mental representation of social relationships, little research has been conducted on associations between individual differences in the implementation 
of the models and normal personality or psychopathology. Haslam, Reichert, and Fiske (2002) obtained several predicted associations between personality disorder symptomatology and broad tendencies to implement and be invested in particular relational models. Relatively strong tendencies to implement Authority Ranking in personal relationships were associated with a wide range of personality disorder symptoms, but were independent of the interpersonal tendencies captured by the interpersonal circumplex (e.g., Kiesler, 1983). Caralis and Haslam (2004) demonstrated a number of links between individual differences in implementation of the relational models and the five-factor model of personality, with Neuroticism, for example, correlating with relatively high implementation of Authority Ranking and Market Pricing and relatively low implementation of Communal Sharing and Equality Matching. These two studies point to promising links between personality and patterns of implementation of the relational models, consistent with the view that people experiencing psychological disturbance may conduct their relationships in atypical ways. However, no studies to date have investigated personality diatheses or axis I mental disorders, or examined how particular relationship types are cognized.

Bearing in mind these considerations, this paper reports the first examination of how atypical ways of implementing the relational models are associated with trait indicators of risk for serious psychopathology (i.e., psychosis, bipolar and unipolar affective disorder), in an undergraduate sample. We examined how the relational models were implemented within particular relational types, as higher levels of vulnerability for psychopathology might be manifest in atypical use of particular models in particular interpersonal contexts.

Although the study was preliminary, employing an unselected rather than "at risk" sample, we approached it with three predictions drawn from the research literature. First, we predicted that vulnerability to unipolar depression would be associated with unusually strong implementation of Communal Sharing and Authority Ranking. Interpersonal dependency and reassurance seeking are associated with depression (e.g., Coyne \& Whiffen, 1995; Joiner \& Schmidt, 1998), and Haslam et al. (2002) found that dependent personality was associated with relatively strong investment in these relationships. People scoring high on vulnerability to depression should therefore construe and conduct their relationships in an unusually close, communal, and asymmetrical fashion. This may be especially true of close relationships, where dependency and reassurance seeking behaviors are most often expressed (Allen, Gilbert, \& Semedar, 2004). Second, we predicted that people high in psychosis proneness would conceive of relationships as relatively asymmetrical, cold and potentially exploitative, by over implementing Authority Ranking and under implementing Communal Sharing and Equality Matching. Vulnerability to psychosis is associated with deficits in theory of mind, leading to suspiciousness and paranoia within relationships, and Haslam et al. (2002) found that schizotypal personality was associated with relatively strong implementation of Authority Ranking in relationships. Third, we predicted that people relatively high in vulnerability to bipolar disorder would demonstrate abnormalities in implementation of relational models in typically hierarchical relationships where Authority Ranking is the usual mode of interaction. We predicted that such people's explicit view of themselves as unusually powerful and attractive may render them likely to treat relationships 
with superiors in ways that are overly close and egalitarian (i.e., relatively high in Communal Sharing and Equality Matching).

\section{METHOD}

\section{Participants}

Participants were 350 undergraduate volunteers, 295 women and 55 men, who received course credit for their participation. They ranged in age from 16 to 49 ( $M=$ $19.8, S D=4.4)$ and were ethnically diverse (50.0\% Anglo-Australian, $28.7 \%$ Asian, 6.2\% European, 3.1\% Asian-Australian, $2.1 \%$ Indian, $6.2 \%$ other).

\section{Materials}

\section{Modes of Relationship Questionnaire (MORQ)}

The MORQ is a 32-item self-report measure (Haslam \& Fiske, 1999) for assessing personal relationships in terms of RM theory. Items were constructed to sample multiple social domains (decision making, distribution and use of resources, exchange, identity, moral evaluations, social influence, work, and other) and are rated from 0 (not at all true of this relationship) to 6 (very true of this relationship). Confirmatory factor analysis (Haslam \& Fiske, 1999) supports the coherence of the four 8 -item scales, and previous studies have obtained scale reliabilities between 0.8 and 0.9.

Following standard practice (e.g., Haslam, 1994), participants freely listed 40 personal acquaintances and rated the relationship they had with every fourth acquaintance on the 32 items. By this means a broad and representative sample of 10 personal relationships was rated. Each relationship was scored on each relational model scale, with scores equaling the mean item rating on each scale. In addition, participants were instructed to identify the role that each of the 10 selected acquaintances had towards them, using ten listed categories (family member, close friend, fellow student, business associate, acquaintance, fellow colleague, tutor, boss, economic relationship, and other).

General Behavior Inventory (GBI; Depue \& Klein, 1988; Depue, Krauss, Spoont, \& Arbisi, 1989)

The GBI is a 73-item self-report inventory designed to identify individuals at risk of mood disorders, assessing enduring affective symptom patterns. It contains three scales-dysphoria, hypomania, and biphasic - which are rated on four-point frequency-based scales. Research has validated the GBI's concordance with blind diagnoses based on informant reports (Depue et al., 1981) and with clinician ratings of subaffective symptoms (Goodnick et al., 1986). Studies have demonstrated associations between GBI scores and mood disorders in first-degree relatives (Depue et al., 1981; Klein, Depue, \& Slater, 1986), and shown that the GBI predicts enduring impairment (Klein \& Depue, 1984). In the current sample the mean, standard deviation, minimum and maximum scores (respectively) on the three GBI scales 
were as follows; dysphoria $(6.94,8.41,0,41)$, hypomania $(2.45,2.99,0,18)$, biphasic $(1.51,1.60,0,6)$.

\section{Chapman Scales}

Three scales developed by Chapman, Chapman and colleagues were employed to detect psychosis-prone participants. The Magical Ideation scale (Eckblad \& Chapman, 1983), the Perceptual Aberration scale (Chapman, Chapman, \& Raulin, 1978) and the Revised Social Anhedonia scale (Mishlove \& Chapman, 1985), containing 30, 35, and 40 items, respectively, assess psychosis-related symptomatology and were designed for use with normal populations. These self-report inventories are among the most widely used self-report measures of psychosis-proneness, and have well-establish psychometric credentials (Chapman, Chapman, \& Kwapil, 1995). Ten-year follow-up and retrospective studies (Chapman, Chapman, Kwapil, Eckblad, \& Zinser, 1994; Kwapil, Miller, Zinser, Chapman, \& Chapman, 1997; Kwapil, 1998) have found that high scorers have an increased risk of experiencing clinical psychosis or psychotic symptoms. A combination of high scores on the Magical Ideation and Social Anhedonia scales was particularly predictive of future psychosis. In the current sample the mean, standard deviation, minimum and maximum scores (respectively) on the three Chapman scales were as follows; magical ideation $(6.15,4.50,0,24)$, perceptual aberration $(4.10,4.07,0,27)$, social anhedonia $(7.25,5.53,0,35)$.

\section{Procedure}

Groups of 5 to 20 undergraduate participants completed the questionnaire packet in a classroom setting in the presence of one investigator.

\section{RESULTS}

Analyses addressed how dimensions of psychological vulnerability are associated with distinctive relational patterns. These analyses focused on particular relationship types to determine how, if at all, more vulnerable individuals construe and implement certain kinds of relationships. Four relationship types were selected in an effort to sample relationships that were ecologically salient and prototypic of each of the relational models, so that possible deviations from normative relational patterns could be examined. "Family member" was common, occurring in the relationship samples of 327 of the 350 participants, and also had the highest mean ratings of all the relationship types on the Communal Sharing scale. "Close friend" was the most common relationship type, occurring in 338 of the participants' samples, and combined high mean ratings on the Communal Sharing and Equality Matching scales. "Fellow student" was another salient relationship type, with its highest rating on Equality Matching, and was listed by 238 participants. "Boss" and "tutor" (akin to teaching assistant in the North American system) had the two highest mean scores on the Authority Ranking scale, and occurred in 62 and 76 relationship samples, respectively. In view of their similar relational profiles, these relationship 
Table I. Mean (SD) MORQ Scale Ratings for Each Relationship Type

\begin{tabular}{lcccc}
\hline & Communal sharing & Equality matching & Authority ranking & Market pricing \\
\hline Family member & $3.59(1.19)$ & $3.20(1.12)$ & $3.02(1.29)$ & $2.26(.87)$ \\
Friend & $3.29(.95)$ & $4.02(.91)$ & $1.59(.96)$ & $2.66(.73)$ \\
Fellow student & $2.18(.95)$ & $3.75(1.03)$ & $1.28(.86)$ & $2.81(.80)$ \\
Boss/tutor & $1.73(1.04)$ & $2.38(1.05)$ & $3.75(1.29)$ & $2.96(.94)$ \\
\hline
\end{tabular}

types were combined to yield a satisfactory sample for statistical analyses (126). "Economic relationship" was most prototypic for MP. However it occurred in only 19 of the relationship samples, allowing insufficient statistical power, and was not investigated further. Thus the four selected relationship types consist of the most prototypic types for Communal Sharing, Equality

Matching and Authority Ranking in addition to the most commonly reported type.

Participants' scores on each MORQ scale for each relationship type were computed as follows. If participants listed no relationship of a particular type in their personal relationship sample they were excluded from any analysis concerning that type. If they listed one relationship of a particular type its score on the relevant MORQ scale (possible range 0-6) was used. If they listed more than one such relationship, their mean scale score across these relationships was used. Thus analyses of relational tendencies associated with psychological vulnerability were based on at least one personal relationship for each included participant. Mean scale scores for each relationship type are presented in Table I.

To assess the associations between dimensions of psychological vulnerability and relational patterns, tendencies to construe relationships of each type according to each relational model were simultaneously regressed onto the four vulnerability dimensions. Prior to doing so, the six vulnerability scales were subjected to principal components analysis to extract independent predictor variables and thus to prevent serious multicollinearity. The scree test supported a readily interpretable four-component solution that accounted for $91.0 \%$ of the variance in the intercorrelation matrix. Varimax rotated loadings are presented in Table II. The first component combined the Depression and Biphasic scales of the GBI, which correlated very highly $(r=0.76)$. The second component joined the Magical Ideation and Perceptual Aberration scales, which also correlated very highly $(r=.68)$, leaving the remaining Chapman scale-the Revised Social Anhedonia scale-as the sole loading on the third component. The GBI's Hypomania scale composed the fourth factor. These four factors served as uncorrelated predictors in a series of 16 simultaneous multiple regression analyses-four relationship types by four MORQ scales-that are summarized in Table III. As noted above, these analyses were restricted to those participants who reported at least one personal relationship of the pertinent relationship type, so sample sizes vary from 126 to 338.

Consistent with our first prediction, depression-proneness was associated with relatively high implementation of the Communal Sharing and Authority Ranking models, although these associations were confined to relationships with family members and also with close friends in the latter case. Consistent with our third 
Table II. Varimax Rotated Loadings of Vulnerability Scales

\begin{tabular}{lclrr}
\multicolumn{4}{c}{ (Decimal Omitted) } \\
\hline & \multicolumn{4}{c}{ Component } \\
\cline { 2 - 5 } & I & II & III & IV \\
\hline Depression (GBI) & 91 & 14 & 09 & 20 \\
Biphasic (GBI) & 89 & 16 & 07 & 23 \\
Hypomania (GBI) & 38 & 19 & -02 & 90 \\
Social anhedonia (RSA) & 11 & 08 & 99 & -02 \\
Magical ideation (MIS) & 08 & 90 & 06 & 18 \\
Perceptual aberration (PAS) & 20 & 90 & 06 & 05 \\
Percentage variance & 30.2 & 28.4 & 16.7 & 15.7 \\
\hline
\end{tabular}

prediction, hypomania was associated with relatively high implementation of the Communal Sharing and Equality Matching models in authority relationships, with the former association also obtained for relationships with close friends.

Associations between psychosis-proneness and implementation of the relational models were somewhat more complex. Consistent with our second prediction, participants scoring relatively high on psychosis-proneness had relatively cold (low Communal Sharing and Equality Matching) relationships. For social anhedonia, this association only reached significance for family and boss/tutor relationships, and for positive psychosis-proneness it held only for Equality Matching relationships with fellow students. Also as predicted, psychosis-proneness was associated with higher levels of Authority Ranking, although only in family and close friend relationships.

Table III. Summary of Regression Analyses (Standardized Beta Coefficients and Overall Model F Values) Predicting Relational Patterns from Vulnerability Components

\begin{tabular}{|c|c|c|c|c|c|}
\hline & \multicolumn{5}{|c|}{ Vulnerability component } \\
\hline & Dysthymia & Hypomania & Social anhedonia & Psychosis & $\mathrm{F}$ \\
\hline \multicolumn{6}{|l|}{ Communal sharing } \\
\hline Family member & $.14^{*}$ & .08 & $-.12^{*}$ & .11 & $4.10^{* *}$ \\
\hline Close friend & .03 & $.15^{* *}$ & -.10 & .06 & $2.87^{*}$ \\
\hline Fellow student & .07 & .01 & -.10 & -.11 & 1.42 \\
\hline Boss/tutor & .09 & $.31^{* *}$ & -.08 & -.06 & $2.62^{*}$ \\
\hline \multicolumn{6}{|l|}{ Equality matching } \\
\hline Family member & $.12^{*}$ & .09 & $-.17^{* *}$ & .02 & $3.87^{* *}$ \\
\hline Close friend & .02 & .08 & -.05 & -.02 & 0.75 \\
\hline Fellow student & .11 & .04 & -.06 & $-.19^{* *}$ & $2.86^{*}$ \\
\hline Boss/tutor & .06 & $.35^{* * * *}$ & $-.19^{*}$ & -.14 & $3.97^{* *}$ \\
\hline \multicolumn{6}{|l|}{ Authority ranking } \\
\hline Family member & $.11^{*}$ & .04 & .06 & $.20^{* * * *}$ & $4.45^{* *}$ \\
\hline Close friend & $.13^{*}$ & .07 & $.16^{* *}$ & $.12^{*}$ & $5.04^{* * *}$ \\
\hline Fellow student & .03 & .06 & .03 & .10 & 0.91 \\
\hline Boss/tutor & .09 & .04 & -.11 & -.02 & 0.57 \\
\hline \multicolumn{6}{|l|}{ Market pricing } \\
\hline Family member & .07 & .09 & -.03 & .04 & 1.20 \\
\hline Close friend & .07 & $.16^{* *}$ & .03 & .05 & $2.77^{*}$ \\
\hline Fellow student & .13 & .09 & -.02 & -.05 & 1.30 \\
\hline Boss/tutor & .04 & .15 & -.14 & .00 & 1.00 \\
\hline
\end{tabular}

${ }^{*} p<.05 .{ }^{* *} p<.01 .{ }^{* * *} p<.001$. 
In sum, of the 34 associations relevant to the three study predictions, 12 were statistically significant and 29 were in the predicted direction. With one exception (positive psychosis-proneness and Communal Sharing), every significant predicted association was observed for at least one of the relationship types.

In addition to the predicted associations, it is interesting to note that implementation of the Market Pricing model was not associated with any of the vulnerability dimensions. A similar observation can be made about relationships with fellow students. Closer, more intimate and involving relationships, and relationships with authority figures, seem more apt to reveal associations with psychological vulnerability.

\section{DISCUSSION}

Although they are preliminary and largely exploratory, and do not offer a rigorous test of the specificity of the associations between relational models and vulnerability dimensions, our findings offer promising support for the proposition that vulnerability to major forms of psychopathology is associated with distinctive ways of understanding and implementing social relationships. Each vulnerability dimension was associated with particular ways of construing personal relationships with family members, close friends, student peers, or authority figures. These associations were generally modest in magnitude and tended not to generalize across relationship types.

The picture that emerges of the relational tendencies associated with dysthymia is quite plausible. Individuals high in depression-proneness may have unusually complicated family relationships. These relationships, which are normatively close, appear to be apprehended by more dysthymic participants in an especially communal fashion. This pattern might be reflected in heightened desires and demands for closeness, care and support, and in failure to respect and acknowledge family members' autonomy; a pattern that is very consistent with excessive reassurance seeking behavior that has been previously associated with vulnerability to depression (Coyne, 1976; Joiner \& Schmidt, 1998). The relatively high levels of Authority Ranking construal of family relationships among people scoring high on dysthymia may similarly indicate overheated or over-invested family relationships, consistent with proposals that depressed individuals subordinate themselves in the hope of eliciting care (Sloman \& Gilbert, 2000). This last pattern was also obtained with close friendships, consistent with the view that depression-prone people may act in a dependent fashion in search of reassurance and support, particularly in close relationships where such demands of support are more likely to be tolerated (Allen, Gilbert, \& Semedar, 2004). As they pertain to the Communal Sharing and Authority Ranking models, these findings are consistent with our expectations, and with past work linking dependency with relatively strong use of these models (Haslam et al., 2002).

These relational patterns may be associated with significant problems for depression-prone individuals. Communal Sharing and Authority Ranking elements are common in family relationships, but implementing them to usually strong degrees may be linked to intense and ambiguous relationships that are marked 
by conflict and high levels of emotional expression (Hooley, 1986). The tendency to apprehend close friendships in asymmetrical (Authority Ranking) terms may also be associated with interpersonal problems. Friends are likely to feel that people who interact on this basis are violating the expectation of egalitarian balance and making unreasonable demands for direction and care. This pattern is consistent with Coyne's(1976) account, which proposes that the depressed person's reassurance-seeking (i.e., positioning of self as subordinate) is associated with interpersonal rejection. Both family conflict and rejection by friends are stressors that might help to precipitate depression among the vulnerable (e.g., Monroe, Rohde, Seeley, \& Lewinsohn, 1999; Rudolf, Hammen, Burge, Lindberg, Herzberg, \& Daley, 2000), so relational tendencies associated with elevated depressionproneness may contribute to the triggering of this vulnerability. Consistent with this, Joiner, Alfano, and Metalsky (1992) reported that the degree of reassurance seeking engaged in by depressed persons was crucial to the likelihood of rejection by their college roommates, with those seeking greater levels of reassurance being more likely to experience rejection.

The relational patterns associated with vulnerability to bipolar disorder imply different kinds of interpersonal conflict. As predicted, higher levels of hypomania were associated with tendencies to apprehend relationships with authority figures in unusually communal and egalitarian ways. This construal represents a violation of expectations for such relationships, as it frames them as relatively warm and conducted by equals. The "superior" in such relationships may perceive this framing as a sign of excessive familiarity, disrespect, and insubordination and may attempt to correct or punish this behavior. Relationships with employers and other supervisors might therefore be particular risky for people prone to bipolar disorder. This atypical pattern of perceiving superiors may provide a partial explanation for previous findings indicating high correlations between hypomania and poor job-performance (e.g., Bartol, 1991).

The vulnerability dimensions normally understood to reflect psychosisproneness are associated with less clear-cut relational tendencies. The more "negative" features captured by social anhedonia are plausibly associated with an unusually weak tendency to apprehend some relationship types in terms of the typically warmer Communal Sharing and Equality Matching models. In addition, socially anhedonia is associated with viewing relationships with close friends as unusually asymmetrical. This association is also evident among individuals scoring relatively high on the positive features of psychosis-proneness. Whether such findings are mediated by social cognitive deficits, such as impaired theory of mind abilities (Frith \& Corcoran, 1996), will need to be addressed by future research. Nevertheless, the high Authority Ranking pattern obtained was consistent with prediction, and with the schizotypy-related findings of Haslam et al. (2002).

The findings offer preliminarysupport the ability of some relational models to capture aspects of the interpersonal style associated with psychological vulnerability. The Communal Sharing, Authority Ranking and Equality Matching models, in particular, showed preliminary evidence of being implicated in vulnerability-related interpersonal profiles. This broad finding is consistent with Haslam et al.'s (2002) finding that many personality disorders were associated with 
atypical implementation of these models. It is theoretically important because some of these models are not captured by most prominent models of interpersonal behavior employed in the study of abnormal psychology. Tendencies to construe relationships in ranked (Authority Ranking) or egalitarian (Equality Matching) terms are conceptually and empirically distinct from the dimensions of the interpersonal circle (e.g., Kiesler, 1983) and of Benjamin's (1996) structural analysis of social behavior (SASB) model. The circle describes individuals' behaviors along an axis of power or dominance, but cannot capture tendencies to apprehend relationships as involving differentials on this axis. For example, it can describe a person's behavior as unusually dominating, but not his or her tendency to apprehend relationships in terms of dominance and submission. The SASB model's axes involve independence versus interdependence and warmth versus coldness, neither of which reflects $\mathrm{Au}-$ thority Ranking or Equality Matching. The RMs therefore appear to cover distinct and potentially fruitful interpersonal ground from the more familiar schemes.

Many of the associations between relational patterns and vulnerability dimensions are weak, and their practical importance could be questioned. However, even when whole-sample correlations are modest, individuals who score in the top few percentiles on the vulnerability dimensions will tend to have substantially atypical relational patterns. That is, the individuals who are at most elevated risk of developing fully-fledged disorders may be relationally atypical despite the small samplewide associations. Nevertheless, our exploratory analysis does not allow a strong or rigorous test of this possibility, and until the associations between vulnerabilities and relational models are found to be robust in a less exploratory investigation they must remain provisional. Moreover, the large number of associations tested raises the likelihood of Type 1 errors, making replication of our findings particularly important. The import of our findings may extend to etiological and prevention issues. If people at increased risk for major mental disorders tend to construe and conduct their personal relationships in atypical ways, then they are likely to experience above average levels of interpersonal discord and rejection in their interactions. Relationships about which participants hold discrepant understandings tend to be unsatisfying, poorly coordinated, and prone to failure, and research shows that discrepancies also commonly produce moral indignation and upset in the interactants (Fiske \& Tetlock, 1997). Such interpersonal failure, rejection, and strife have been repeatedly implicated as stressors capable of triggering mental disorders in vulnerable individuals (e.g., Hooley, Orley, \& Teasdale, 1986; Monroe et al., 1999; Rudolph et al., 2000). In a cruel irony, the relational tendencies associated with vulnerabilities to psychopathology may tend to elicit just the sorts of stressors that exacerbate these vulnerabilities.

The findings of the present study are preliminary and in the most part exploratory, and further research is needed to develop and test predictions of its relational model-based account of vulnerability. Future research should identify truly "at risk" samples who score high on the vulnerability dimensions, study their relational cognition and actual interpersonal behaviors, develop more specific hypotheses, test more rigorously the specificity of associations between vulnerability dimensions and particular relational models, and employ more multi-method assessment of both vulnerability and relational patterns. Nevertheless, the study offers 
encouraging support for a new account of the interpersonal markers of psychological risk. Investigating the distinct and atypical ways in which people perceive and construct their relationships is a neglected approach to the study of vulnerability. However this relational approach is one that complements more established lines of interpersonal vulnerability research that focuses on personality traits, information processing biases, dysfunctional beliefs, and social skill deficits. Understanding the role that cognition about relationships plays in vulnerability to mental disorders is therefore a promising topic for further investigation.

\section{REFERENCES}

Allen, N. B., \& Badcock, P. B. T. (2003). Social risk and depressed mood: Evolutionary, psychosocial, and neurobiological perspectives. Psychological Bulletin, 129, 887-913.

Allen, N. B., Gilbert, P., \& Semedar, A. (2004). Depression as an interpersonal strategy: The importance of relational models. In N. Haslam (Ed.), Relational models theory: A contemporary overview (pp. 309-334). Mahwah, NJ: Lawrence Erlbaum and Associates.

Badcock, P. B. T., \& Allen, N. B. (2003). Adaptive social reasoning in depressed mood and depressive vulnerability. Cognition and Emotion, 17, 647-670.

Bartol, C. R. (1991). Predictive validation of the MMPI for small town police officers who fail. Professional Psychology; Research and Practice, 22, 127-132.

Benjamin, L. S. (1996). Interpersonal diagnosis and treatment of personality disorders (2nd ed.). New York: Guilford.

Bentall, R. P. (2001). Social cognition and delusional beliefs. In P. W. Corrigan \& D. L. Penn (Eds.), Social cognition and schizophrenia (pp. 123-148). Washington, DC: American Psychological Association.

Blanchard, J. J., Mueser, K., \& Bellack, A. S. (1998). Anhedonia, positive and negative affect, and social functioning in schizophrenia. Schizophrenia Bulletin, 24, 413-424.

Broks, P. (1997). Brain, self, and others: The neuropsychology of social cognition. In G. Claridge (Ed.), Schizotypy: Implications for illness and health (pp. 98-123) Oxford: Oxford University Press.

Caralis, D., \& Haslam, N. (2004). Personality correlates of the relational models. Psychology and Psychotherapy: Theory, Research and Practice, 77, 397-402.

Chapman, J. P., Chapman, L. J., \& Kwapil, T. R. (1995). Scales for the measurement of schizotypy. In A. Raine \& T. Lencz (Eds.), Schizotypal personality (pp. 79-106). New York: Cambridge University Press.

Chapman, L. J., Chapman, J. P., Kwapil, T. R., Eckblad, M., \& Zinser, M. C. (1994). Putatively psychosisprone subjects 10 years later. Journal of Abnormal Psychology, 103, 171-183.

Chapman, L. J., Chapman, J. P., \& Raulin, M. L. (1978). Body-image aberration in schizophrenia. Journal of Abnormal Psychology, 87, 399-407.

Corrigan, P. W., \& Toomey, R. (1995). Interpersonal problem solving and information processing in schizophrenia. Schizophrenia Bulletin, 21, 395-404.

Coyne, J. C. (1976). Toward and interactional description of depression. Psychiatry, 39, 28-40.

Coyne, J. C., \& Whiffen, V. E. (1995). Issues in personality as diathesis for depression: The case of sociotropy-dependency and autonomy-self-criticism. Psychological Bulletin, 118, 358-78.

Depue, R. A., \& Klein, D. N. (1988). Identification of unipolar and bipolar affective conditions in nonclinical and clinical populations by the General Behavior Inventory. In D. L. Dunner, E. S. Gershon, \& J. E. Barrett (Eds.), Relatives at risk for mental disorders (pp. 179-202). New York: Raven Press.

Depue, R. A., Krauss, S., Spoont, M. R., \& Arbisi, P. (1989). General Behavior Inventory identification of unipolar and bipolar affective conditions in a non-clinical university population. Journal of Abnormal Psychology, 98, 117-126.

Depue, R. A., Slater, J. F., Wolfstetter-Kausch, H., Klein, D. N., Goplerud, E., \& Farr, D. (1981). A behavioral paradigm for identifying persons at risk for bipolar depressive disorder: A conceptual framework and five validation studies. Journal of Abnormal Psychology, 90, 381-437.

Dohr, K. B., Rush, A. J., \& Bernstein, I. H. (1989). Cognitive biases and depression. Journal of Abnormal Psychology, 98, 263-267.

Eckblad, M., \& Chapman, L. J. (1983). Magical ideation as an indicator of schizotypy. Journal of Consulting and Clinical Psychology, 51, 215-225. 
Edwards, J., Jackson, H. J., \& Pattison, P. E. (2002). Emotion recognition via facial expression and affective prosody in schizophrenia: A methodological review. Clinical Psychology Review, 22, 789-832.

Fiske, A. P. (1992). The four elementary forms of sociality: Framework for a unified theory of social relations. Psychological Review, 99, 689-723.

Fiske, A. P. (1993). Social errors in four cultures: Evidence about the elementary forms of social relations. Journal of Cross-Cultural Psychology, 24, 67-94.

Fiske, A. P., \& Haslam, N. (1996). Social cognition is thinking about relationships. Current Directions in Psychological Science, 5, 143-148.

Fiske, A. P., \& Tetlock, P. E. (1997). Taboo tradeoffs: Reactions to transactions that transgress spheres of exchange. Political Psychology, 18, 255-297.

Frith, C., \& Corcoran, R. (1996). Exploring "theory of mind" in people with schizophrenia. Psychological Medicine, 26, 521-530.

Goodnick, P. J., Fieve, R. R., Peselow, E., Schlegel, A., \& Filippi, A. (1986). General Behavior Inventory: Measurement of subclinical changes during depression and lithium prophylaxis. Acta Psychiatrica Scandinavica, 73, 529-532.

Haslam, N. (1994). Categories of social relationship. Cognition, 53, 59-90.

Haslam, N. (2004). Research on the relational models: An overview. In N. Haslam (Ed.), Relational models theory: A contemporary overview (pp. 27-57). Mahwah, NJ: Erlbaum.

Haslam, N., \& Fiske, A. P. (1999). Relational models theory: A confirmatory factor analysis. Personal Relationships, 6, 241-250.

Haslam, N., Reichert, T., \& Fiske, A. P. (2002). Aberrant social relations in the personality disorders. Psychology and Psychotherapy: Theory, Research and Practice, 75, 19-31.

Hooley, J. M. (1986). Expressed emotion and depression: Interactions between patients and high- versus low-expressed-emotion spouses. Journal of Abnormal Psychology, 95, 237-46.

Hooley, J. M., Orley, J., \& Teasdale, J. D. (1986). Levels of expressed emotion and relapse in depressed patients. British Journal of Psychiatry, 148, 642-647.

Joiner, T. E. Jr., \& Schmidt, N. B. (1998). Excessive reassurance seeking predicts depressive but not anxious reactions to acute stress. Journal of Abnormal Psychology, 107, 533-537.

Joiner, T. E., Alfano, M. S., \& Metalsky, G. I. (1992). When depression breeds contempt: Reassurance seeking, self-esteem, and rejection of depressed college students by their roommates. Journal of Abnormal Psychology, 101, 165-173.

Johnson, S. L., \& Meyer, B. (2003). Psychosocial predictors of symptoms. In S. L. Johnson \& R. Leahy (Eds.), Psychological treatment of bipolar disorder. New York, NY: Guilford Press.

Kiesler, D. J. (1983). The 1982 interpersonal circle: A taxonomy for complementarity in human transactions. Psychological Review, 90, 185-214.

Klein, D. N., \& Depue, R. A. (1984). Continued impairment in persons at risk for bipolar affective disorder: Results of a 19-month follow-up study. Journal of Abnormal Psychology, 94, 115127.

Klein, D. N., Depue, R. A., \& Slater, J. F. (1986). Inventory identification of cyclothymia: IX. Validation in offspring of bipolar 1 patients. Archives of General Psychiatry, 43, 441-445.

Klein, D. N., Lewinsohn, P. M., \& Seeley, J. (1996). Hypomanic personality traits in a community sample of adolescents. Journal of Affective Disorders, 38, 135-143.

Kwapil, T. R. (1998). Social anhedonia as a predictor of the development of schizophrenia-spectrum disorders. Journal of Abnormal Psychology, 107, 558-565.

Kwapil, T. R., Miller, M. B., Zinser, M. C., Chapman, J., \& Chapman, L. J. (1997). Magical ideation and social anhedonia as predictors of psychosis proneness: A partial replication. Journal of Abnormal Psychology, 106, 491-495.

Lewinsohn, P. M., Steinmetz, J. L., Larson, D. W., \& Franklin, J. (1981). Depression related cognitions: Antecedent or consequence? Journal of Abnormal Psychology, 91, 213-219.

Lyon, H. M., Bentall, R. P., \& Startup, M. (1999). Social cognition and the manic defense: Attributions, selective attention, and self-schema in bipolar affective disorder. Journal of Abnormal Psychology, 108, 273-282.

Mathews, A., Ridgeway, V., \& Williamson, D. A. (1996). Evidence for attention to threatening stimuli in depression. Behaviour Research and Therapy, 34, 695-705.

Mishlove, M., \& Chapman, L. J. (1985). Social anhedonia in the prediction of psychosis proneness. Journal of Abnormal Psychology, 94, 384-396.

Monroe, S. M., Rohde, P., Seeley, J. R., \& Lewinsohn, P. M. (1999). Life events and depression in adolescence: Relationship loss as a prospective risk factor for first-onset of major depressive disorder. Journal of Abnormal Psychology, 108, 606-614.

Neale, J. M. (1988). Defensive functions of manic episodes. In T. F. Oltmanns \& B. A. Maher (Eds.), Delusional beliefs (pp. 138-156). New York: Wiley. 
Penn, D. L., \& Corrigan, P. W. (2001). Social cognition in schizophrenia: Answered and unanswered questions. In P. W. Corrigan \& D. L. Penn (Eds.), Social cognition and schizophrenia (pp. 315-322). Washington, DC: American Psychological Association.

A1

Penn, D. L., Corrigan, P. W., Bentall, R. P., Racenstein, J. M., \& Newman, L. S. (1997). Social cognition in schizophrenia. Psychological Bulletin, 121, 114-132.

Penn, D. L., Spaulding, W. D., Reed, D., \& Sullivan, M. (1996). The relationship of social cognition towards behavior in chronic schizophrenia. Schizophrenia Research, 20, 327-335.

Rudolf, K. D., Hammen, C., Burge, D., Lindberg, N., Herzberg, D., \& Daley, S. E. (2000). Toward an interpersonal life-stress model of depression: The developmental context of stress generation. Development and Psychopathology, 12, 215-234.

Sacco, W. P. (1999). A social cognitive model of interpersonal processes in depression. In T. Joiner \& J. Coyne (Eds.), The interactional nature of depression: Advances in interpersonal approaches (pp. 329-362). Washington, DC: American Psychological Association.

Segrin, C., \& Abramson, L. Y. (1994). Negative reactions to depressive behaviors: A communication theories analysis. Journal of Abnormal Psychology, 103, 655-668.

Sloman, L., \& Gilbert, P. (2000). Subordination and defeat: An evolutionary approach to mood disorders and their therapy. Mahwah, NJ: Lawrence Erlbaum Associates. 


\section{Queries to Author:}

A1: Au: Penn and Corrigan (2001) is not cited in the text. Please check. 